\title{
CuO and MWCNTs Nanoparticles Filled PVA-PVP Nanocomposites: Morphological, Optical, Thermal, Dielectric, and Electrical Characteristics
}

Hassan A. H. Alzahrani ( $\sim$ hahalzahrani@uj.edu.sa )

University of Jeddah

\section{Research Article}

Keywords: Nanocomposites, PNCs, Nanofillers, PVA, PVP

Posted Date: November 30th, 2021

DOI: https://doi.org/10.21203/rs.3.rs-1115784/v1

License: (c) (1) This work is licensed under a Creative Commons Attribution 4.0 International License.

Read Full License

Version of Record: A version of this preprint was published at Journal of Inorganic and Organometallic Polymers and Materials on January 31st, 2022. See the published version at https://doi.org/10.1007/s10904-022-02233-z. 


\title{
$\mathrm{CuO}$ and MWCNTs Nanoparticles Filled PVA-PVP
} Nanocomposites: Morphological, Optical, Thermal, Dielectric, and Electrical Characteristics

\author{
Hassan A. H. Alzahrani ${ }^{1^{*}}$ \\ ${ }^{1}$ Department of Chemsitry, College of Science and Arts at Khulis, University of Jeddah, P.O. Box 355, Jeddah, \\ Saudi Arabia. \\ *Corresponding author:hahalzahrani@uj.edu.sa
}

\section{Abstract}

Copper dioxide $(\mathrm{CuO})$ nanoparticles and Multiwall carbon nanotubes (MWCNTs) filled poly(vinyl alcohol) (PVA) and poly(vinyl pyrrolidone) (PVP) blend matrix (50/50 wt\%) based polymer nanocomposites (PNCs) (i.e., PVA/PVP:(15-x)CuO(x)MWCNTs for $\mathrm{x}=0,1,5,7.5,10,14$, and $15 \mathrm{wt} \%$ ) have been prepared employing the solution-cast method. The morphologies of these PNCs are semicrystalline, according to an X-ray diffraction investigation. The FTIR, SEM, and AFM measurements of PNCs were used to investigate the development of the miscible mix, polymer-polymer and polymer-nanoparticle interactions, and the influence of $\mathrm{CuO}$ and MWCNTs nanofillers on the morphology aspects on the main chain of PVA/PVP blend. The nanofiller dispersion signposting for $\mathrm{x}=14 \mathrm{wt} \%$ nanoloading in the PVA-PVP blend matrix significantly enhances the crystalline phase, diminishing the optical energy gap to $2.31 \mathrm{eV}$. The DC conductivity values augment with the upsurge in nanofiller level for maximum $\mathrm{x}=14 \mathrm{wt} \%$. The dielectric and electrical characteristics of these PNCs are investigated for an applied frequency range from $1 \mathrm{kHz}$ to $1 \mathrm{MHz}$. The enhancement in the nanofiller level upto $\mathrm{x}=14 \mathrm{wt} \%$ in the PVA/PVP matrix leads to the development of percolating network through the PNCs. These factors boost the dielectric permittivity values substantially, owing to the decrease in the nano-confinement phenomenon. The rise in applied frequency reduces dielectric permittivity and impedance values and enhances ac electrical 
conductivity. These PNCs having good dielectric and electrical characteristics can be used as frequency tunable nanodielectric material in electronic devices.

Keywords: Nanocomposites, PNCs, Nanofillers, PVA, PVP

\section{Introduction}

Nowadays, engineering polymers have become a part of polymers, which are persistently suitable for high temperatures with strong structural, optical and electronic properties, excellent geometrical durability, strong weather resilience, and fatigue strength [14]. In this regard, polymer mixing, or a blend of polymers, is a class of engineering polymers identical to metallic ingots obtained by combining a minimum of two polymers to produce a distinct substance with varied fundamental characteristics $[5,6]$. The creation of polymer blends involves many distinct procedures such as melting, solution blending, latex melding, partial blocking or grafting copolymerisation and developing interpenetrating polymeric networks $[7,8]$. Out of these procedures, as mentioned above the solvent blending is a highly economical and simplest way of production of polymer blends. The procedure includes the mixing of two or more polymers that are frequently immiscible and have compatible components. The compatibility should increase the regularity of the microstructures and the functionality of that substance regarding structural and bonding characteristics. The Poly(vinyl alcohol) (PVA) and Poly(vinyl pyrrolidone) (PVP) mixture have developed remarkable qualities in this respect, having excellent characteristics such as high elasticity, flexibility, non-toxicity, good mechanical strength and are thermally stable materials. [9-11]. The additional benefits of these combinations include water-soluble, miscible, excellent electro-optic properties and composite materialising characteristics $[12,13]$. Many researchers are involved in their innovative investigation using PVA-PVP mixtures filled with nanoparticles to create a new polymer blend nanocomposite (PNCs) for any appropriate 
device applications $[14,15]$. Out of many fillers, nanoparticles to be incorporated in the polymer matrix, the copper oxide $(\mathrm{CuO})$, and multiwall carbon nanotubes (MWCNTs) have emerged as excellent nanofillers due to versatile applications in present-day technology $[16,17]$. The $\mathrm{CuO}$ nanoparticles belong to a class of transition metal oxide, with monoclinic structures and p-type semiconducting properties. These highly stable $\mathrm{CuO}$ nanofillers also have fascinating features such as exceptional thermophysical abilities, good dispersion ability, photovoltaic capabilities, and antibacterial activity [18]. On the other hand, other nanofiller multiwall carbon nanotubes (MWCNTs) contain many popped graphene sheets comprising structural complexity and variation. Conversely, MWNTs benefit from massive manufacturing facilities, the cheap unit expense of production, improved thermodynamic features, and chemically resilient materials. These MWCNTs are applicable in sensitive gas detection materials, dielectric and technologically challenging applications, such as fieldemission and optoelectronic screens [19]. In this current research, we have developed PVAPVP:(15-x)CuO(x) MWCNTs nanocomposite by utilizing solvent casting method for various filler level $x=0,1,5,7.5,10,14,15 \mathrm{wt} \%$. The solvent casting method's advantages involve obtaining uniform thickness, better gloss, flexibility, economical, and no defects (die lines, extrusion, etc.) composites. The prepared PVA-PVP:(15-x)CuO(x) MWCNTs PNCs are further used to explore its structural, optical, dielectric and electronic properties for any possible device applications.

\section{Materials and Methods}

\subsection{CuO Nanoparticles}

Throughout the research work, only essential laboratory solution grades were employed to synthesise $\mathrm{CuO}$ nanofillers. The reagents $\left(\mathrm{Cu}\left(\mathrm{C}_{2} \mathrm{H}_{3} \mathrm{O}_{2}\right)_{2}\right)$ and $\mathrm{NaOH}$ used during this current study are procured by Sigma Aldrich, Germany. Eventually, $0.02 \mathrm{~mol}$ of liquid copper acetate mixture is prepared by adding $1 \mathrm{ml}$ glacial acetic acid and boiled at $110^{\circ} \mathrm{C}$ at a 
continuous mixing rate of $500 \mathrm{rpm}$ for 1 hour using a temperature-controlled mechanical agitator. Subsequently, $1 \mathrm{M} \mathrm{NaOH}$ acid is transferred to the sample described above solutions such that a dark cloud is generated. The precipitation induced throughout the combination is extracted to create copper oxide nanofillers using a centrifuge. This $\mathrm{CuO}$ aggregate is repeatedly rinsed using deionising water until all $\mathrm{NaOH}$ residues with neutrality $\mathrm{pH}$ values are eliminated. The obtained $\mathrm{CuO}$ was subsequently dried for eight hours to eliminate the humidity component at $500^{\circ} \mathrm{C}$ in an oven, and the estimated yield was about $94 \%$. XRD and SEM were evaluated to explore the crystallographic phase formation of $\mathrm{CuO}$ powder.

\subsection{Preparation of Carboxylated MWCNTs}

Carbon nanotubes are externally modified to introduce unique characteristics such as increased functionality dispersal, compatibility, or reduced toxic effects. Thus, $75 \mathrm{mg}$ of Multi-walled carbon nanotubes (MWCNTs with $3.5 \mathrm{~nm}$ diameter, 1 - $10 \mu \mathrm{m}$ length having purity $>90 \%$ and specific surface area $>500 \mathrm{~m}^{2} / \mathrm{g}$ ) was purchased through Sigma Aldrich, Germany and dipped in hydrochloric acid $(\mathrm{HCl})$ for 24 hours. These drenched MWCNTs in $\mathrm{HCl}$ solution is mixed with $500 \mathrm{ml}$ of distilled water and swirled using a vigorous stirring rate of 500rpm approximately for 20 minutes. The stirred mixture was further filtered utilising pore $0.1 \mu \mathrm{m}$ Whatman Nylon filter membrane. The acquired remnant mixture is repeatedly treated thoroughly till the $\mathrm{pH}$ level of the filtrated mixture becomes neutral. Subsequently, produced MWCNTs were dried in the vacuum oven maintained at $600^{\circ} \mathrm{C}$ for 20 hours to eliminate the water component. Finely, altered MWCNTs were disseminated in sulfuric acid $\left(\mathrm{H}_{2} \mathrm{SO}_{4}\right)$ and nitric acid $\left(\mathrm{HNO}_{3}\right)$ combination obtained in 3:1 volume proportion and homogenised by utilising probe ultrasonicator (PCI Analytics, India) for 2 hours. The dispersed mixture is rinsed with distilled water until the filtrated solution is neutral and then screened using a $0.1 \mu \mathrm{m}$ Whatman Nylon filter membrane. The precursor is heated in a 
vacuum oven, and the quantity of the carboxylated MWCNTs generated (MWCNT-COOH) is $73.2 \mathrm{mg}$.

\subsection{PVA/PVP Polymer Nanocomposites}

8g of Mowiol 4-88 of (PVA of Sigma Aldrich Germany, average molecular weight 31000) are mixed into $80 \mathrm{ml}$ deionised water and agitated for an hour at $90^{\circ} \mathrm{C}$ temperature to produce a clear liquid. Likewise, $80 \mathrm{ml}$ deionised water was mixed to $8 \mathrm{~g}$ of Poly vinyl pyrrolidone (PVP, average molecular weight 40000, Sigma Aldrich Germany). This combination is agitated at $70^{\circ} \mathrm{C}$ and 500rpm for two hours to produce a suitable liquid. The clear, viscous liquid was again mixed (at 300rpm) for 1 hour at room temperature employing a mechanical stirrer. The dense mixture formed is partitioned into eight equal portions. This PVA-PVP :(15-x)CuO(x) MWCNTs nanocomposites of various ' $\mathrm{x}$ ' nanofiller loading are produced by the subsequent equation,

$$
\mathrm{x} \%=\frac{\mathrm{w}_{\mathrm{d}}}{\left(\mathrm{w}_{\mathrm{d}}+\mathrm{w}_{\mathrm{p}}\right)} X 100
$$

where $\mathrm{W}_{\mathrm{d}}$ is the weight of the added nanofillers and $\mathrm{W}_{\mathrm{p}}$ is the weight of the host polymer blend.

Synthesised $\mathrm{ZnO}$ and MWCNTs nanofillers have been introduced with a weight of $\mathrm{x}=0,1,5,7.5,10,14$ and 15 . Furthermore, fill the nanofillers on every area of the PVA/PVP mix employing ultrasonicator for 10 minutes, unless every nanofillers are uniformly dispersed. Each part of PVA-PVP:(15-x)CuO(x)MWCNTs solution is placed on a glass petri plate and stored in a furnace set at $50^{\circ} \mathrm{C}$ for drying tonight. Every nano-composites film is stripped and enveloped inside a silver sheet and stored inside a vacuum chamber for additional analysis. 


\subsection{Measurements}

The overall thickness of PVA-PVP:(15-x)CuO(x)MWCNTs PNCs were estimated 165-180 $\mu$ m employing a DektaK stylus profilometer (Bruker). The structural parameters of PVA-PVP:(x)CuO(15-x) MWCNTs for different nanofiller loading are detected by the Empyrean third-generation Malvern Panalytical X-ray Diffractometer in the $\mathrm{Cu}-\mathrm{K} \alpha$ reflections $(\mu=1,5406 \mathrm{~A})$. Using $\mathrm{KBr}$ Pellets Varian Excalibur FTIR Spectrometer in the 500 to $4000 \mathrm{~cm}^{-1}$ range, the FTIR spectra of PNCs are acquired with 50 scans and $2 \mathrm{~cm}^{-1}$ precision. SEM EVO 18 ALTO 1000 cryo-scanning model is employed to study the morphological structure, particle size estimate, and content of PVA-PVP:(15-x)CuO(x)MWCNTs nanocomposites. The surface roughness and morphological developments were obtained utilizing the solver-PRO (NT-MDT) AFM instrument. In an environmental chamber at heating intervals of $10{ }^{\circ} \mathrm{C} / \mathrm{min}$, the heat degradation was studied in a range of temperatures from 35 to $650{ }^{\circ} \mathrm{C}$ adopting a Shimadzu Thermogravimetric-45H. The visible spectrometer Shimadzu UV is used to assess the optical properties such as energy gap. The dielectric loss tangent of PVA-PVP:(15-x)CuO(x)MWCNTs for real and complicated dielectric nanocomposites is evaluated employing the 4200-SCS Keithley parameter analyser at rooms from $1 \mathrm{kHz}$ to $1 \mathrm{MHz}$ across frequency bands. PL spectra were produced from a photoluminescent spectrum by fluorescence spectrophotometer-Cary eclipse (Varian) by utilising emission and arousal slit size $5 \mathrm{~nm}$, scanning rate $120 \mathrm{~nm} / \mathrm{min}$, data interval $1 \mathrm{~nm}$ (average time $0.5 \mathrm{~s}$ ), PMT voltage $600 \mathrm{~V}$, and exc $=325 \mathrm{~nm}$ wavelength by excitation.

\section{Results and Discussions}

\subsection{XRD spectra}

Figure 1 illustrates the XRD spectra of PVA-PVP:(15-x)CuO(x)MWCNTs at loading levels of the ' $x$ ' filled compound, $x$ ranging from $0,1,5,7.5,10,14$, and 15 wt $\%$. Filled MWCNTs exemplify a slight bump in the MWCNTs' diffraction angle at 26.52 degrees (JCPDS file no: 48-1449) [20]. On the other hand, peaks arise at $2 \theta=21.6^{\circ}, 29.7^{\circ}, 36.5^{\circ}, 42.4^{\circ}$, 
and $61.4^{\circ}$, analogous to (014), (110), (111), (200), and (113) orientation signpost the presence of $\mathrm{CuO}$ nanoparticles [21]. A comprehensive, substantial rise at scattering angle $19^{0}<2 \theta<$ $20^{0}$ can be seen, which suggests the existence of the semicrystalline peak of PVA (more precisely, of polyvinyl acetate). The peak witnessed at $21.21^{0}$, corresponding to d-values of $4.1544 \AA$, indicates the PVP polymer long chain [21]. The breadth of semicrystalline peaks of PVA-PVP nanocomposite varies due to incorporating nanofillers, which reveals an increase in the crystalline parameters. The strength of the crystallised spikes of PVA-PVP rises in tandem with the filler level, and the findings are most pronounced for the filler level $\mathrm{x}=14 \%$. Enhancing complex conformation involves the OH group of PVA-PVP backbone sequence and $\mathrm{CuO} / \mathrm{MWCNT}$ nanofillers, which leads to gain in the crystalline phase. Thus, PVA-PVP peaks move onto the lesser angle with the upsurge in filler level.

Table 1 Crystalline values of PVA-PVP/(15-x)CuO(x)MWCNTs

\begin{tabular}{ccccc}
\hline $\begin{array}{c}\text { Dopants } \\
\text { concentrations }\end{array}$ & $\begin{array}{c}\text { \% } \\
\text { Crystallinity }\end{array}$ & $\begin{array}{c}\text { D } \\
(\mathbf{n m})\end{array}$ & $\begin{array}{c}\text { Microstrain } \\
(\boldsymbol{\varepsilon}) \mathbf{x ~ 1 0}\end{array}$ & $\begin{array}{c}\boldsymbol{\delta} \mathbf{~ ( 1 0}^{\mathbf{3}} \\
\left.\text { lines/m}^{\mathbf{2}}\right)\end{array}$ \\
\hline Pure PVA-PVP & 53.85 & 3.79 & 12.94 & 6.9618 \\
$0 \mathrm{wt} \%$ & 54.13 & 9.89 & 4.313 & 1.022 \\
$1 \mathrm{wt} \%$ & 54.77 & 10.06 & 4.224 & 0.988 \\
$5 \mathrm{wt} \%$ & 55.33 & 10.91 & 3.780 & 0.840 \\
$7.5 \mathrm{wt} \%$ & 56.99 & 11.78 & 2.133 & 0.720 \\
$10 \mathrm{wt} \%$ & 57.67 & 12.52 & 1.997 & 0.637 \\
$14 \mathrm{wt} \%$ & 58.92 & 13.88 & 1.487 & 0.519 \\
$15 \mathrm{wt} \%$ & 56.71 & 12.59 & 1.812 & 0.630 \\
\hline
\end{tabular}

Table 1 further depicts the microstructural strain (also known as strain), dislocation density (also known as density), and crystallinity (also known as phase) of each PVA-PVP :(15-x) $\mathrm{CuO}(\mathrm{x}) \mathrm{MWCNTs}$ for various filler loading. The crystallite size in polymer nanocomposite measures the molecular disorder by implanting nanoparticles in the PVA-PVP polymer's backbone. We have developed an algorithm using PowderX software (http://powdex.eng.umich.edu) to enunciate the crystallinity behaviour of composite materials. The results are shown as relative intensities $\left(I / I_{0}\right)$, where I refer to the intensity in counts at any peaks, whereas $\mathrm{I}_{0}$ signpost intensity of the notable crystalline peak. The 
existence of intrinsic filler ions throughout the crystalline state interstitial locations of the PVA-PVP backbone may alternatively be viewed as a PVA main chain with the nanofillers [22]. The maximum crystallinity is seen when ' $x$ ' represents the filler weight concentration and is equal to 14 percent. Recrystallisation may also play a role in the surprising variance in defect characteristics of the nanocomposites. Because of these characteristics, the structural regularities of the PVA-PVP host molecule alter with the loading of MWCNTs and $\mathrm{CuO}$ nanofillers [23]. Hence, these variables result in enhancing the crystallinity of PVA-PVP blended nanocomposites. 


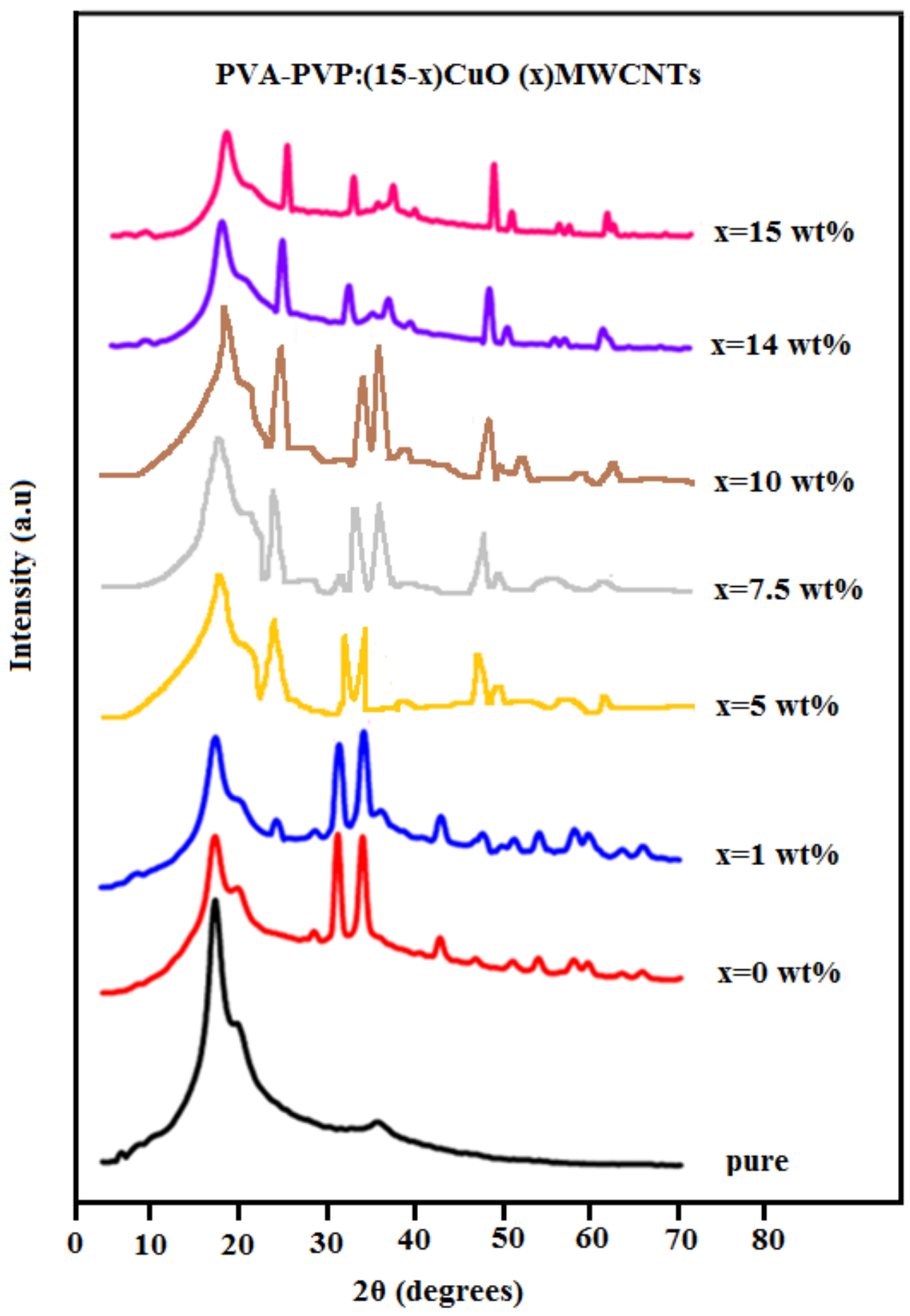

Figure 1: XRD spectra of PVA-PVP:(15-x)CuO(x)MWCNTs PNCs

\subsection{Atomic Force Microscopy( AFM)}

The AFM analysis in tapping mode is to analyse the surface shape and roughness of the prepared composites. Figures 2(a) and 2(b) show AFM pictures of nanocomposite for pure and optimum filler level $\mathrm{x}=10 \mathrm{wt} \%$ in two-dimensional (2D) views. Using the AFM topography, the root-medium-square (RMS) surface roughness of the composites are assessed 
in the scan area specified in table 2. RMS surface ruggedness measures are $1.3 \mathrm{~nm}$, correspondingly for $\mathrm{x}=14 \mathrm{wt} \%$ nano-composites. The addition of nanofiller MWCNTs and $\mathrm{CuO}$ into the PVA/PVP blend enhances the roughness of the RMS varies considerably upto $\mathrm{x}=14 \mathrm{wt} \%$ filler level. Enhancement in the roughness of the RMS signpost the increase in the crystalline characteristics of nanocomposites. AFM photos also show the rapid twodimensional Fourier (FFT) transformation of the related pictures. This 2D FFT transforms spatial information into the frequency domain, which is extremely useful for understanding the morphology of the nanocomposite surface. The white dots are the periodicity of surface morphology in the FFT pictures [24]. It is evident that for $\mathrm{x}=14 \mathrm{wt} \%$ filler level, the white point density is greater than in the pure PVA//PVP blend film. We may thus infer that MWCNTs and $\mathrm{CuO}$ nanofillers are randomly orientated into the PVA/PVP matrix that provides a big spot of dispersed intensity at the centre. Figure 3 signifies the 3-D photographs of PVA-PVP:(15-x)CuO(x)MWCNTs for $\mathrm{x}=14 \mathrm{wt} \%$ nanofiller concentration. AFM measurements acquired particle height ranging upto $33.7 \mathrm{~nm}$ and also mean particular diameter of approximately $118.43 \mathrm{~nm}$ within the PVA/PVP matrix.

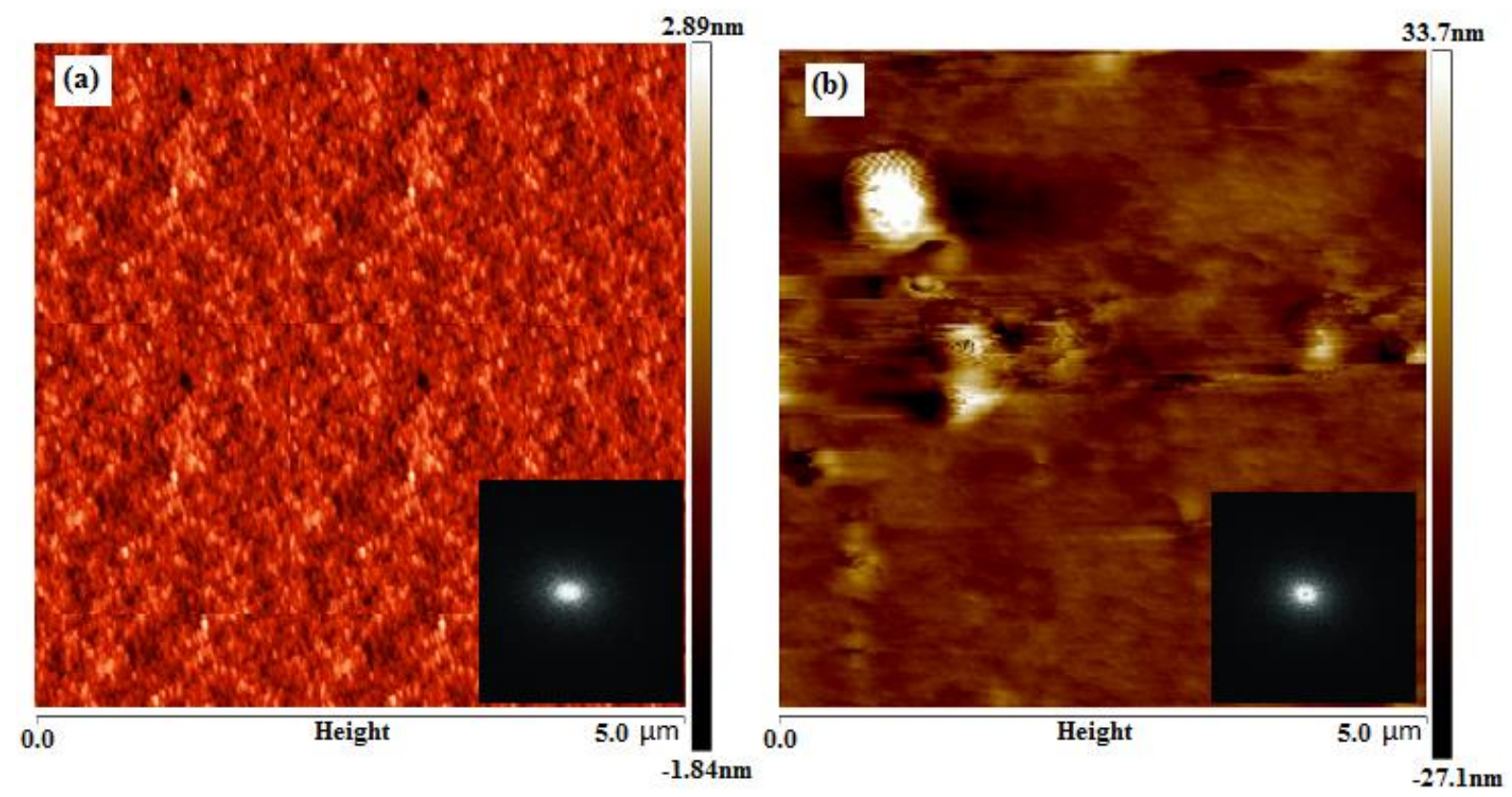

Figure 2: AFM 2-Dimension photographs with FFT transforms spatial information of (a) Pure PVA and (b) PVA/PVP filled MWCNTs and $\mathrm{CuO}$ nanofillers for $\mathrm{x}=14 \mathrm{wt} \%$ filler concentration. 


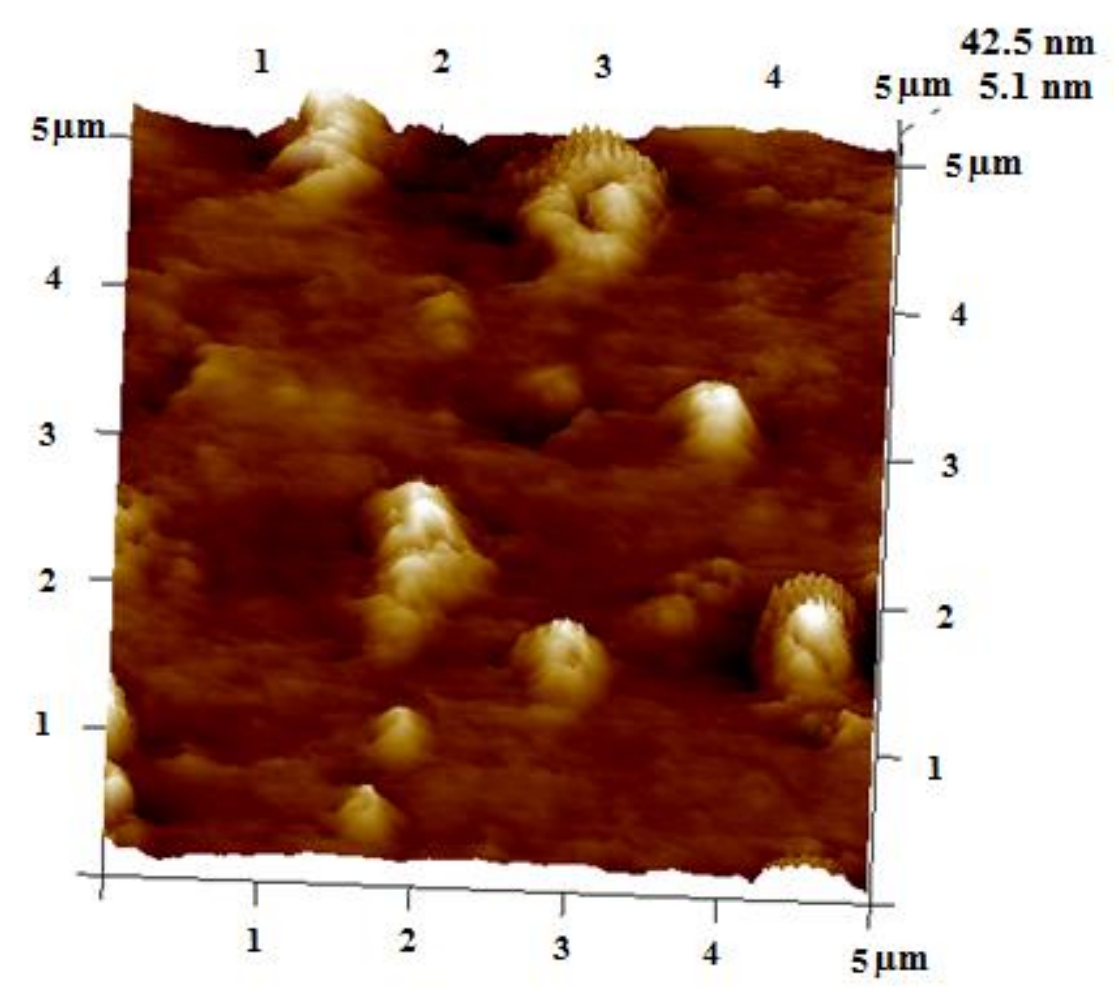

Figure 3: AFM 3-Dimension photograph of PVA-PVP (15-x)CuO(x)MWCNTs for $x=14 w t \%$

Table 2: AFM parameters of PVA-PVP:(15-x)CuO (x)MWCNTs of optimum filler loading $\mathrm{x}=14 \mathrm{wt} \%$

\begin{tabular}{lllll}
\hline Parameter & Mean & Minimum & Maximum & Sigma \\
\hline Total Count & 8.000 & 8.000 & 8.000 & 0.000 \\
Density & $0.320\left(/ \mu \mathrm{m}^{2}\right)$ & $0.320\left(/ \mu \mathrm{m}^{2}\right)$ & $0.320\left(/ \mu \mathrm{m}^{2}\right)$ & $0.000\left(/ \mu \mathrm{m}^{2}\right)$ \\
Height & $14.508(\mathrm{~nm})$ & $5.172(\mathrm{~nm})$ & $42.576(\mathrm{~nm})$ & $14.187(\mathrm{~nm})$ \\
Area & $58031.082\left(\mathrm{~nm}^{2}\right)$ & $9536.743\left(\mathrm{~nm}^{2}\right)$ & $\begin{array}{l}321960.438 \\
\left(\mathrm{~nm}^{2}\right)\end{array}$ & $\begin{array}{l}100274.750 \\
\left(\mathrm{~nm}^{2}\right)\end{array}$ \\
& & & $640.260(\mathrm{~nm})$ & $164.844(\mathrm{~nm})$ \\
\hline
\end{tabular}

\subsection{Scanning Electron Microscopy (SEM)}

Figure 4 refers to SEM surface morphology, indicating that the $\mathrm{CuO}$ and MWCNTs are evenly distributed in PVA-PVP mixtures of optimum loading level $14 \mathrm{wt} \%$ percent. Figure 4 also shows that the PVA-PVP mixture has a strong relationship with $\mathrm{CuO}$ and MWCNTs 
nanofillers forming a homogenous nanocomposite film. The binding among the MWCNTs and $\mathrm{CuO}$ nanofillers increases with a reasonably optimum concentration $\mathrm{x}=14 \mathrm{wt} \%$. The high concentration of only MWCNTs or $\mathrm{CuO}$ nanofillers limits ( $\mathrm{x}=15 \mathrm{wt} \%$ or $\mathrm{x}=0 \mathrm{wt} \%$ ) improvement of the structural behaviour of the nanocomposites.

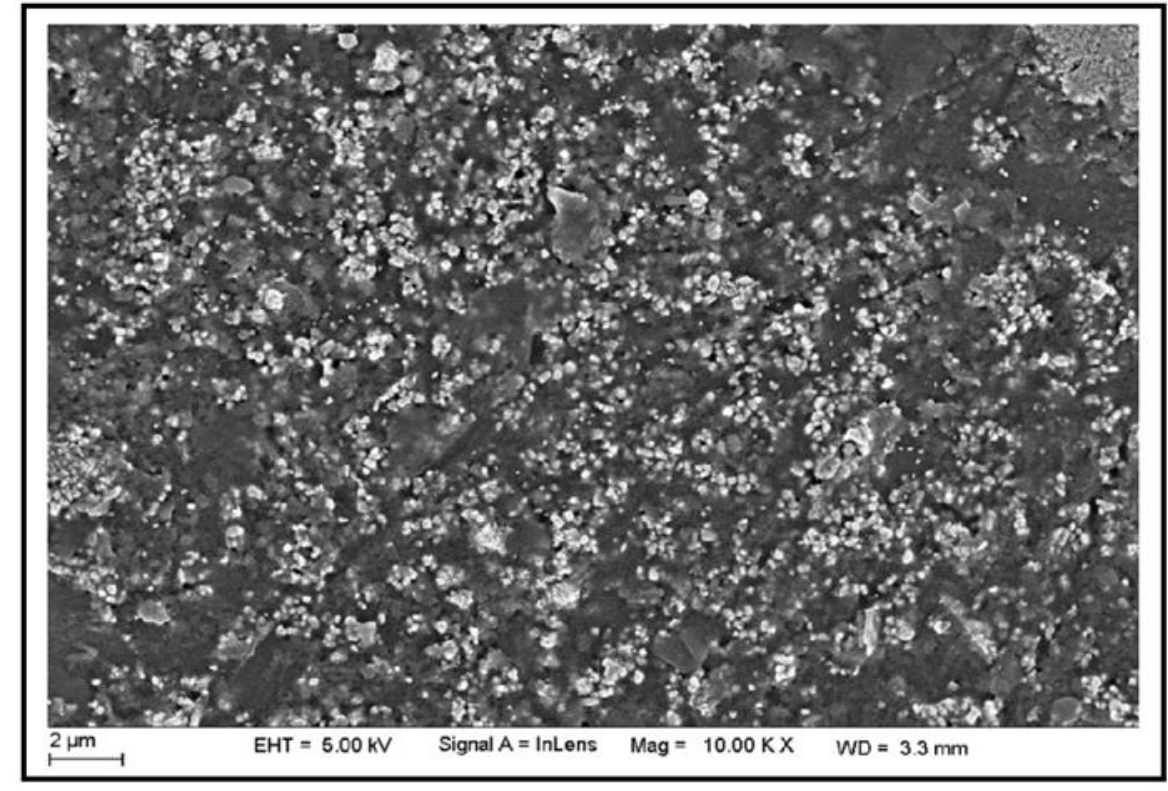

Figure 4: SEM photographs of PVA-PVP:(15-x)CuO(x)MWCNTs for $x=14 w t \%$

\subsection{FTIR spectral analysis}

Figure 5 continuum obtained revealed typical bending as well as stretching vibration of a structural class of fabricated PVA/PVP:(15-x)CuO(x) MWCNTs PNCs. In a pure PVP/PVA blend, the $\mathrm{O}-\mathrm{H}$ straining oscillation indicates the existence of the $\mathrm{O}-\mathrm{H}$ hydroxyl group and is ascribed by the wide and extreme range peaks seen regularly at $2857-3631 \mathrm{~cm}^{-1}$. For the treated PVA/PVP blend, the shifting of the O-H band is observed correspondingly with the rise in nanofiller levels. The surge in filler level upto $x=14 w t \%$ shifts the $\mathrm{OH}$ stretching frequencies to the lower wavenumbers than pure PVA/PVP blends. The interaction of $\mathrm{CuO}$ and MWCNTs nanofillers with PVA/PVP-OH group is responsible for nanocomposites' structural, optical and electronic properties. The narrowing of the hydroxyl band with the rise in nanofillers signposts the semicrystalline nature of the nanocomposite material. The band at $3577 \mathrm{~cm}^{-1}$, the leading $\mathrm{OH}$ vibrational bands of alcohol and phenols, were moved to higher wavenumbers with the rise in nanofillers. The addition of nanofiller upto $\mathrm{x}=14 \mathrm{wt} \%$ resulted in a narrowing of hydroxyl band compared to pure PVA/PVP blend. The peaks recognised at $2570 \mathrm{~cm}^{-1}$ seems to be a typical band of oscillations of C-C of the blend. The three bands at 2492, 2320, and $2141 \mathrm{~cm}^{-1}$ represent the primary chain PVA/PVP 
spectra: $\mathrm{C}-\mathrm{H}$ symmetric distortion, $\mathrm{CH}_{2}$ deformation, and $\mathrm{C}=\mathrm{O}$ stretching interacting with loaded nanofillers [25]. The added nanofillers $\mathrm{CuO}$ and MWCNTs shift some bands towards the lower frequency range in the FTIR spectra. These alterations indicate how all the $\mathrm{C}-\mathrm{H}$ compounds in the PVA/PVP connected with added nanofillers resulting in complex conformations [26]. An active absorption band related to symmetric and asymmetric stretching $\mathrm{C}=\mathrm{O}$ of $\mathrm{PVA} / \mathrm{PVP}$ blend backbone structure is witnessed at $1714-1011 \mathrm{~cm}^{-1}$. The absorption peaks detected at $918 \mathrm{~cm}^{-1}$ represents the syndiotactic structure of PVA/PVP blend. The increase in nanofiller loading enhances the syndiotacticity of PVA/PVP blend, causing dense molecular packing and stronger intermolecular hydrogen bonds. This is responsible for the disappearance of molecular motion resulting in a rise in crystallinity inside the polymer matrix. Thus, the local surface chemistry, internal structural ordering of nanofillers and strain induced by nanofillers with PVA/PVP host matrix resulted in crystalline parameters of PVP/PVA(15-x)CuO(x) MWCNTs PNCs.

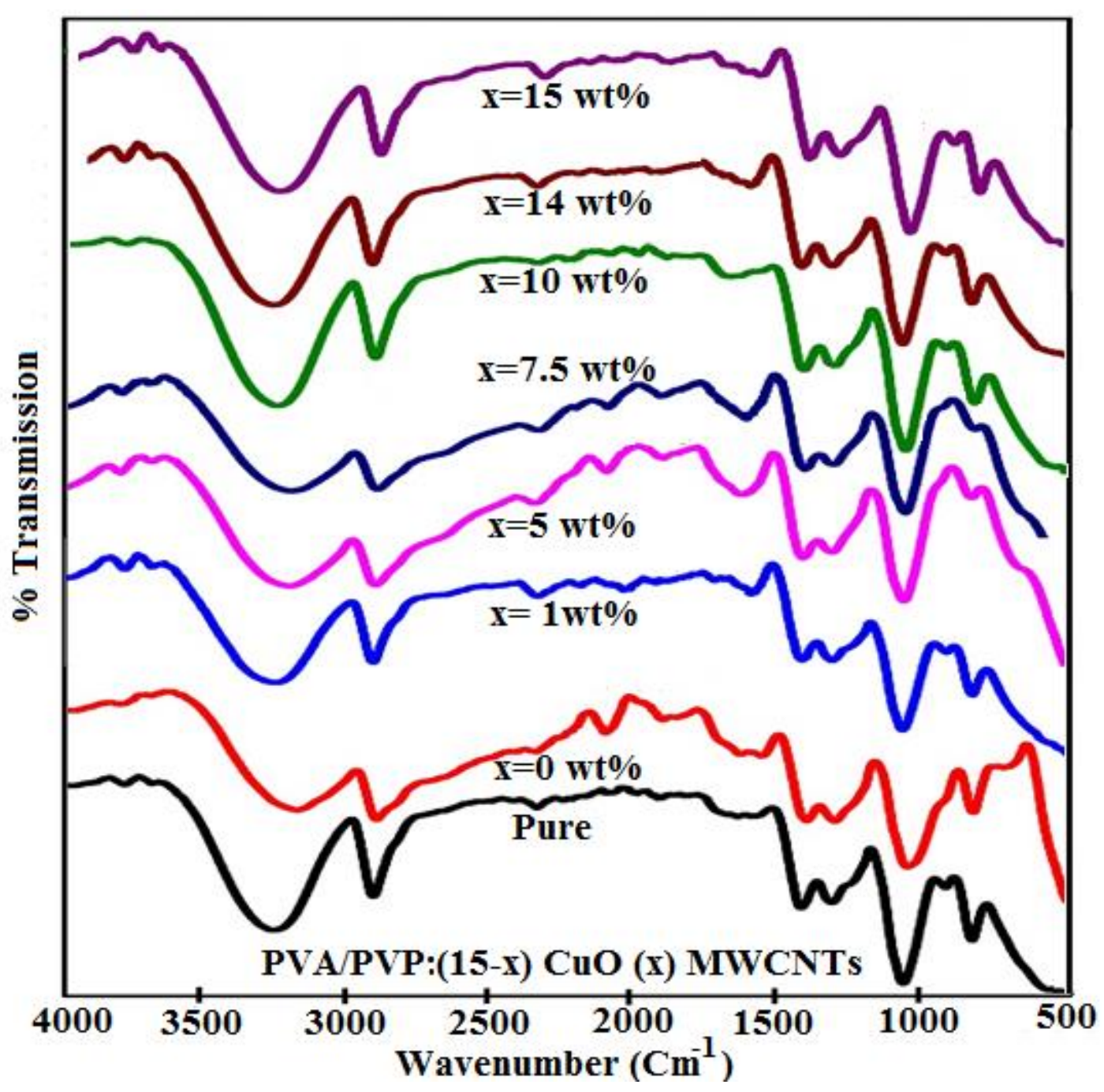

Figure 5: FTIR spectra of PVP/PVA(15-x)CuO(x) MWCNTs PNCs 


\subsection{UV visible spectroscopic studies}

In work conducted to measure the optical properties of PVA-PVP $(15-\mathrm{x}) \mathrm{CuO}(\mathrm{x})$ MWCNTs, ultraviolet-visible spectroscopic results were used. Figure 6 exemplifies the UVvisible spectra of PNCs for several loading levels. The optical absorption coefficient enhances with a higher loading dosage of MWCNTs and $\mathrm{CuO}$ nanofillers. The absorption bands' intensity rises with nanofiller concentration and shows redshifts, suggesting an improvement in charge delocalisation inside the PVA-PVP network. The PVA-PVP primary chain complex interaction with the nanofillers promotes the shift in the absorption band. These complex hydrophobic interactions create more entanglement of nanofillers (complex conformation) with the host matrix, leading to crystalline parameters [27]. The formation of complex conformation found maximum till the filling level reaches $x=14 \mathrm{wt} \%$, thereby changing the wavelength of the absorption peaks leading to maximum absorption intensity. Figure 7 confirms an indirect allowed transition of PVA-PVP:(15-x)CuO(x)MWCNTs PNCs provided by the linear behaviour at ambient temperature. An extension of the linear part of the displayed curve from a measure of optical energy band gap $\mathrm{E}_{\mathrm{g}}$ of the PVA-PVP: $(15-\mathrm{x}) \mathrm{CuO}$ (x) MWCNTs to $(\alpha \mathrm{hv})^{0.5}=0$ produces the outcome of optical energy band gap $\mathrm{E}_{\mathrm{g}}$ of PNCs $[28,29]$. This graph shows the change in the bandgap of PVA-PVP/ (15-x)CuO(x) MWCNTs concerning $x=0,1,5,7.5,10,14$, and $15 \%$, respectively. The diminution in the band gap value $2.31 \mathrm{eV}$ with the rise in filler loading for $\mathrm{x}=14 \mathrm{wt} \%$ is due to occupying nanofillers in the interstitial positions between PVA-PVP chains and promoting complex conformations. These results in a charge exchange process between the nanofillers and PVA-PVP chain network, causing the reduction energy gap enhancing the conductivity in the PVA-PVP/ $(15-\mathrm{x}) \mathrm{CuO}(\mathrm{x})$ MWCNTs nanocomposites. 


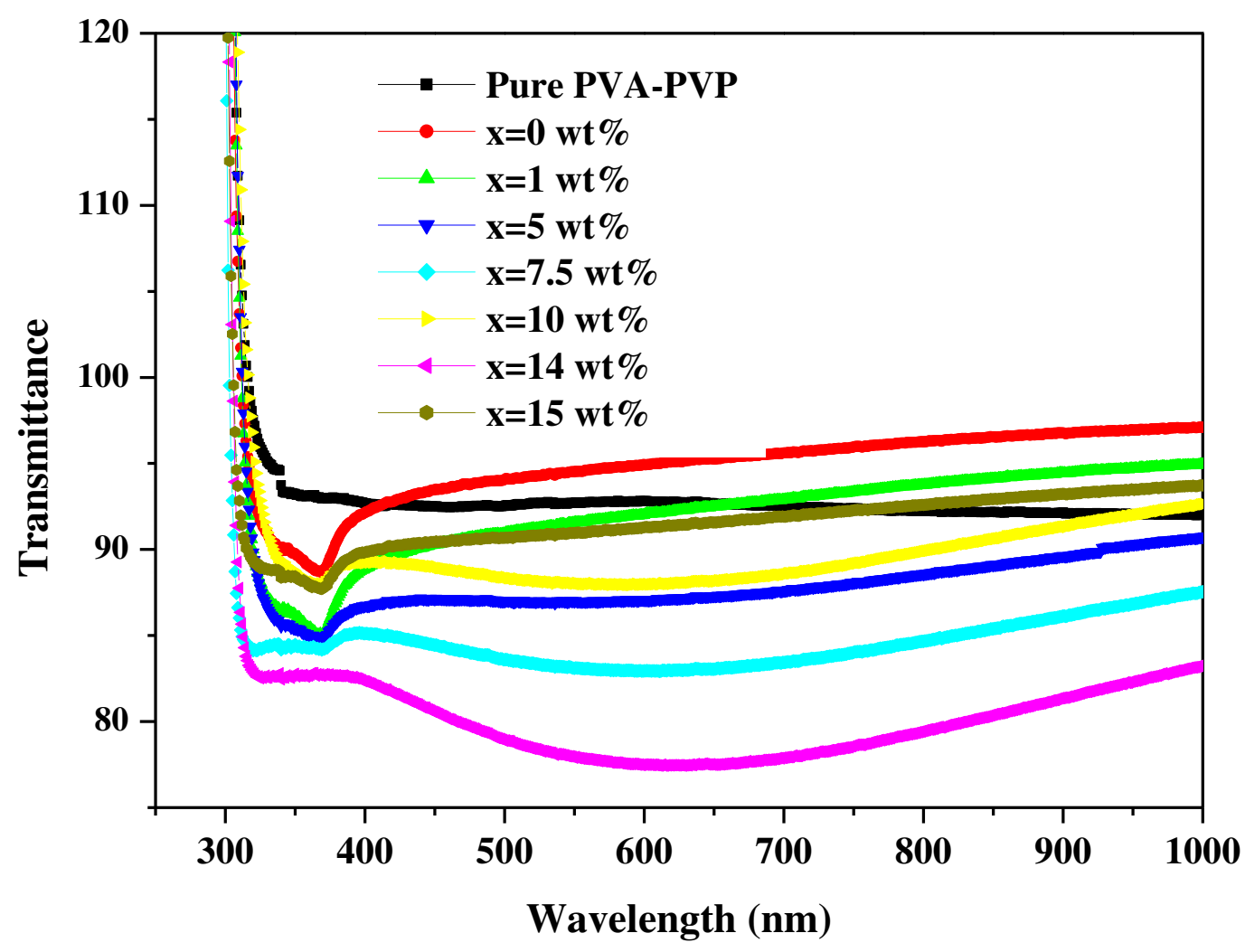

Figure 6: UV visible spectra of PVA-PVP:(15-x)CuO(x)MWCNTs PNCs 


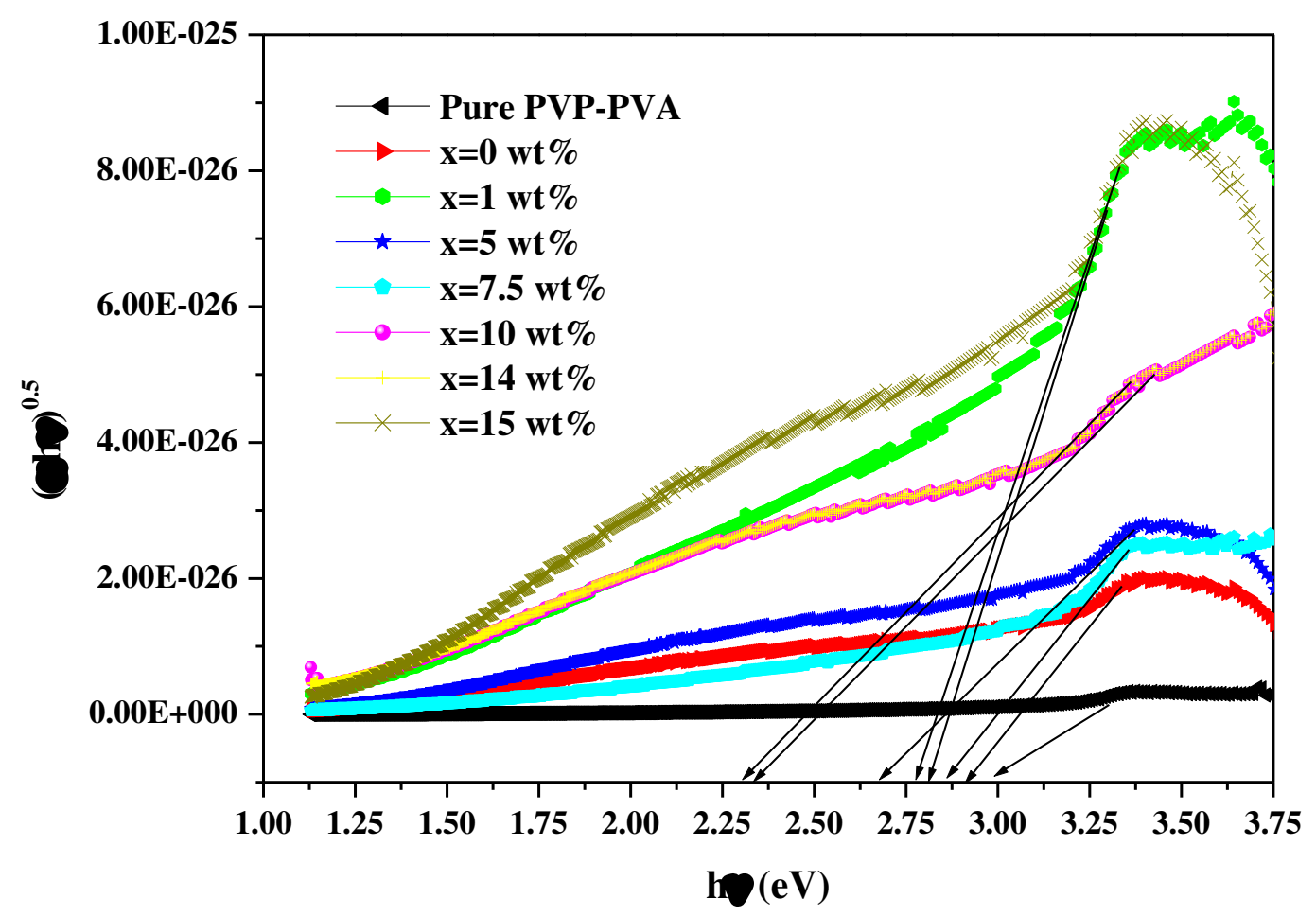

Figure 7: Variation in energy gap ( $\left.\mathrm{E}_{\mathrm{g}}\right)$ of PVA-PVP:(15-x)CuO(x)MWCNTs PNCs

\subsection{Conductivity Studies}

Table 3 explicit the DC electrical conductivity values of MWCNTs along with $\mathrm{CuO}$ nanofillers $(\mathrm{x}=0,1,5,7.5,10,14$ and $15 \mathrm{wt} \%)$ in the PVA-PVP matrix. The DC conductivity of PNCs increases by $13.35 \times 10^{-9} \mathrm{~S} / \mathrm{cm}$ for loading level $\mathrm{x}=14 \mathrm{wt} \%$. The MWCNTs and $\mathrm{CuO}$ nanofillers inside the PVA-PVP chain network promote charge transfer complexes (CTCs) within the nanocomposites. The semicrystalline PVA-PVP nanocomposites that produce CTCs lead to reduced barrier height and, therefore, allow for better conductivity in the amorphous portions of the polymer matrix [30]. The network of PVA-PVP involves a transport mechanism that comprises rapid intrachain wavelike movement produced by the (bi)polaron wave function overlay on the same PVA-PVP chain. This fallout in leaping activity from site to site is initiated by (bi)polaron's interactions with neighbouring chains[31]. The filling of nanofillers creates fluctuations in carrier activity, and mobility may result in lower activation energy. It can be reasonably assumed that MWCNTs and $\mathrm{CuO}$ nanofillers are distributed throughout the amorphous phase and occupy interstitial locations among PVA- 
PVP chains. These added nanofillers connect with the PVA/PVP chain via hydrogen bonds by conducting charge among the nanofillers and the PVAPVP network. CTCs enhance the interfacial barrier and reduce the insulator chain transition probability by decreasing the crystalline-amorphous interface. The percolation hypothesis explains how the nanoparticles can form a conducting route between two charging nodes.

In contrast to the carriage of transporters in neutral conjugated polymers, it is necessary to examine the impact of counter ions. The (bi)polarons are isolated traps produced via coulomb interaction of counterions for the small loading level. The increase in the loading level from $\mathrm{x}=0$ to $14 \%$ lowers coulomb traps and enables intra- and inter-chain mobility to the carriers. For the $\mathrm{x}=14 \mathrm{wt}$ percent optimal filling, these traps overlap by lowering the barrier and promoting movement. Above $\mathrm{x}>14 \mathrm{wt} \%$, the carrier's transportation interchain is significantly influenced by morphology and microstructure circumstances that decrease nanocomposites' conductivity [32].

Table 3: DC conductivity parameters of PVA-PVP:(15-x)CuO(x)MWCNTs PNCs

\begin{tabular}{|c|c|c|c|}
\hline SI No & $\begin{array}{c}\text { Filler } \\
\text { Concentration } \\
(\mathbf{w t} \%)\end{array}$ & Resistance( $(\Omega)$ & $\begin{array}{l}\text { Conductivity } \\
(\sigma \text { in } \mathrm{S} / \mathrm{cm})\end{array}$ \\
\hline 1 & Pure PVA-PVP & $10.534 \times 10^{6}$ & $1.423 \times 10^{-11}$ \\
\hline 2 & 0 & $9.337 \times 10^{6}$ & $1.605 \times 10^{-11}$ \\
\hline 3 & 1 & $8.134 \times 10^{5}$ & $1.841 \times 10^{-10}$ \\
\hline 4 & 5 & $7.970 \times 10^{5}$ & $1.882 \times 10^{-10}$ \\
\hline 5 & 7.5 & $6.334 \times 10^{4}$ & $2.368 \times 10^{-9}$ \\
\hline 6 & 10 & $2.943 \times 10^{4}$ & $5.096 \times 10^{-9}$ \\
\hline 7 & 14 & $1.123 \times 10^{4}$ & $13.35 \times 10^{-9}$ \\
\hline 8 & 15 & $2.278 \times 10^{4}$ & $6.584 \times 10^{-9}$ \\
\hline
\end{tabular}




\subsection{Thermogravimetric Analysis (TGA)}

TGA is an excellent technique for assessing nanocomposite materials' mass changes, heat resistance and thermal decomposition. Figure 8 explores the thermal properties of essential PVP/PVA mix and PNCs PVP/PVA(15-x)CuO(x) MWCNTs with load levels $\mathrm{x}=0,1,5,7.5,10,14$ and $15 \mathrm{wt}$. A significant weight loss between $120^{\circ} \mathrm{C}$ and $255^{\circ} \mathrm{C}$ results in the breakdown of macromolecular chains into tiny fragments [33]. An observed dramatic weight loss over $260{ }^{\circ} \mathrm{C}$ is attributable to the thermal decomposition of the PVA/PVP main chains. In most of the tests, a peak between 550 and $650{ }^{\circ} \mathrm{C}$ was found ascribed to carbonisation and deterioration of the mixture of polymers [34]. The improvement in thermal stability additionally occurs by changing the curves to greater temperatures by raising the loading levels of nanofillers. The increase of thermal stability may be attributable to the good thermal characteristics of added nanofillers, which encourages the heat dissipation in PVA/PVP matrices [35]. The interfacial interaction as well as surface modification between the nanofillers and the PVA/PVP mixture for optimum filler level $\mathrm{x}=14 \mathrm{wt} \%$ may further encourage heat dissipation and effectively postpone the breakdown nanocomposites. The strengthening of the interface contact between MWCNTs with $\mathrm{CuO}$ nanofillers and PVA/PVP PNCs dispersion upto $\mathrm{x}=14 \mathrm{wt} \%$ loading level may perhaps lead to the better thermal stability matched with pure PVA/PVP blend. 


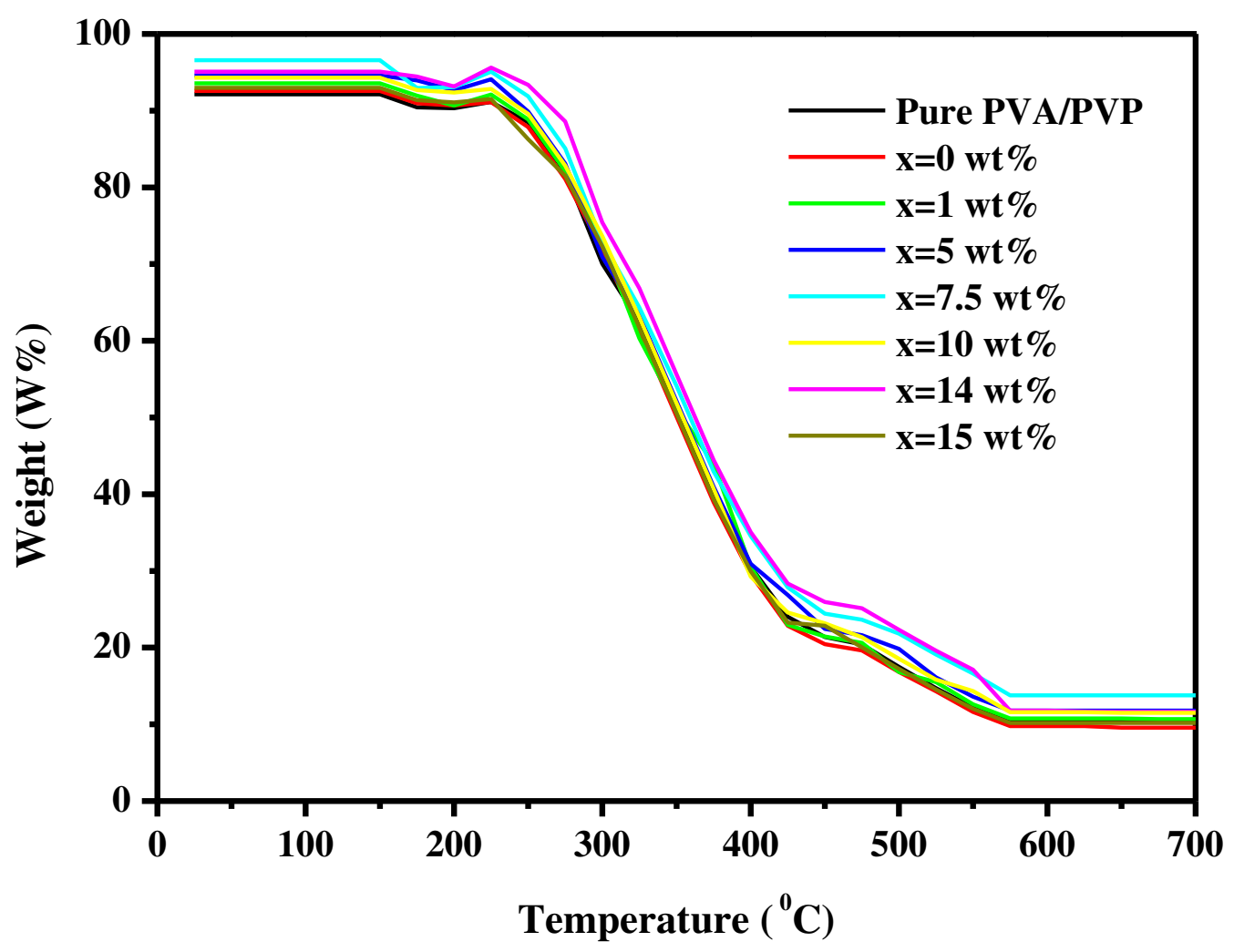

Figure 8: TGA thermograms of PVP/PVA(15-x)CuO(x) MWCNTs PNCs for various filler concentrations

\subsubsection{Calculation of the Activation Energy}

To calculate the thermodynamics parameters obtained from the TGA curves, the following two methods are employed.

\subsubsection{Coats - Redfern method}

It is an example of an integral method in which activation energy analysis is performed as follows [36]:

$$
\log \left[\frac{-\log (1-\alpha)}{T^{2}}\right]=\log \frac{R}{\Delta E_{\alpha}}\left[1-\frac{2 R T}{E_{\alpha}}\right]-0.434 \frac{E_{\alpha}}{R T}
$$


Where, $\mathrm{R}=8.3136 \mathrm{~J} / \mathrm{mol} \mathrm{K}$ ( the universal gas constant), $\mathrm{T}$ signposts the absolute temperature, $\mathrm{E}_{\alpha}$ refers to activation energy $(\mathrm{J} / \mathrm{mol})$ and $\alpha$ denotes weight loss of conversion fraction.

In tracing the dependency of $\log \left[\frac{-\log (1-\propto)}{T^{2}}\right]$ versus $\frac{1000}{\mathrm{~T}}$ related to the individual specimen, a straight line has been achieved and considering the paths, the activation energy may be computed as:

$$
\mathrm{E}_{\alpha}=\text { slope } \times 2.303 \mathrm{R}
$$

\subsubsection{Broido method}

Broido introduces a methodology to determine activation energy during phase two of breakdown employing the formula:

$$
\ln \left[\ln \left(\frac{1}{\mathrm{Y}}\right)\right]=\left(\frac{\mathrm{E}_{\alpha}}{\mathrm{R}}\right) \frac{1}{\mathrm{~T}}+\text { constant }
$$

In the above expression, ' $\mathrm{Y}$ ' gives the number of undecomposed initial molecules and are estimated employing the equation:

$$
\mathrm{Y}=\frac{\mathrm{W}_{\mathrm{t}}-\mathrm{W}_{\infty}}{\mathrm{W}_{\mathrm{i}}-\mathrm{W}_{\infty}}
$$

Where $\mathrm{W}_{\mathrm{t}}, W_{\infty}$, Wi represents the weight, weight zero and first weight at any time $\mathrm{t}$, respectively. A graph of $\ln [\ln (1 / \mathrm{Y})]$ vs $1 / \mathrm{T}$ provides excellent proximity to a straight path. Considering consecutive lines, we computed slope, which gives the activation energy [37]. Table 4 explores the activation energy $\left(\mathrm{E}_{\alpha}\right)$ measurements in Coats - Redfern and Broido technique that diminish the upsurge value in nanofillers loading level upto $x=14 \mathrm{wt} \%$. This shows that the PVA/PVP mix is intensely affected by the presence of nanofillers in its main chain. 
Table 4: Activation energy and percentage crystallinity of unfilled and filled PNCs employing Coats-Redfern and Broido techniques

\begin{tabular}{cccc}
\hline $\begin{array}{l}\text { Nanofiller loading } \\
\text { Concentration } \\
(\mathbf{w t} \%)\end{array}$ & $\begin{array}{l}\text { Coats' } \mathbf{x} \text { ' } \\
\text { method }(\mathbf{K J} / \mathbf{m o l})\end{array}$ & $\begin{array}{l}\text { Redfern } \\
(\mathbf{K J} / \mathbf{m o l})\end{array}$ & $\begin{array}{l}\text { Percentage } \\
\text { Crystallinity }\end{array}$ \\
\hline Pure PVA/PVP & 260.2 & 257.5 & 50.77 \\
$\mathbf{0}$ & 258.3 & 254.9 & 52.84 \\
$\mathbf{1}$ & 254.7 & 250.1 & 53.17 \\
$\mathbf{5}$ & 250.7 & 246.7 & 54.11 \\
$\mathbf{7 . 5}$ & 243.8 & 238.4 & 54.78 \\
$\mathbf{1 0}$ & 236.3 & 231.8 & 55.11 \\
$\mathbf{1 4}$ & 227.6 & 222.7 & 56.34 \\
$\mathbf{1 5}$ & 237.1 & 234.2 & 55.01 \\
\hline
\end{tabular}

\subsection{Photoluminescence}

Figure 15 signposts the photoluminescence of PVP/PVA(15-x)CuO(x) MWCNTs PNCs with a percentage loading levels for $\mathrm{x}=0,1,5,7.5,10,14$ and $15 \mathrm{wt}$, employing fluorescence spectrophotometer-Cary Eclipse. PL is an operational method that estimates electronic structure affected by the complex particle dimension formed due to crystallinity. The PL analyses for produced PNCs were conducted on a surge wavelength of $375 \mathrm{~nm}$ at room temperature. The PNCs exhibit exciting pinnacles at 380nm and precise, strong emission bands within $650 \mathrm{~nm}$ visible range by disregarding a specific harmonic reflection order [38]. The initial strong PL in the near UV-vis regions represents the planar PVA/PVP polymer molecules. The wide emission spectrum found for PVA/PVP nanocomposite correlates to the electronic shift of the $\mathrm{OH}$ side-chain typical of the three different aqueous, isotactic, syndiotactic and atactic polymer configurations [39]. A prominent emission band at $638 \mathrm{~nm}$ resembles the electron-hole recombination of MWCNTs and $\mathrm{CuO}$ nanofillers. The broadband emission of the PL of PVP/PVA(15-x)CuO(x)MWCNTs nanocomposites is attributed by some authors are due to $\mathrm{CuO}$ structural defects (green areas), as oxygen vacancies, and MWCNTs, as well as certain impurities (yellow and orange areas) [40]. 


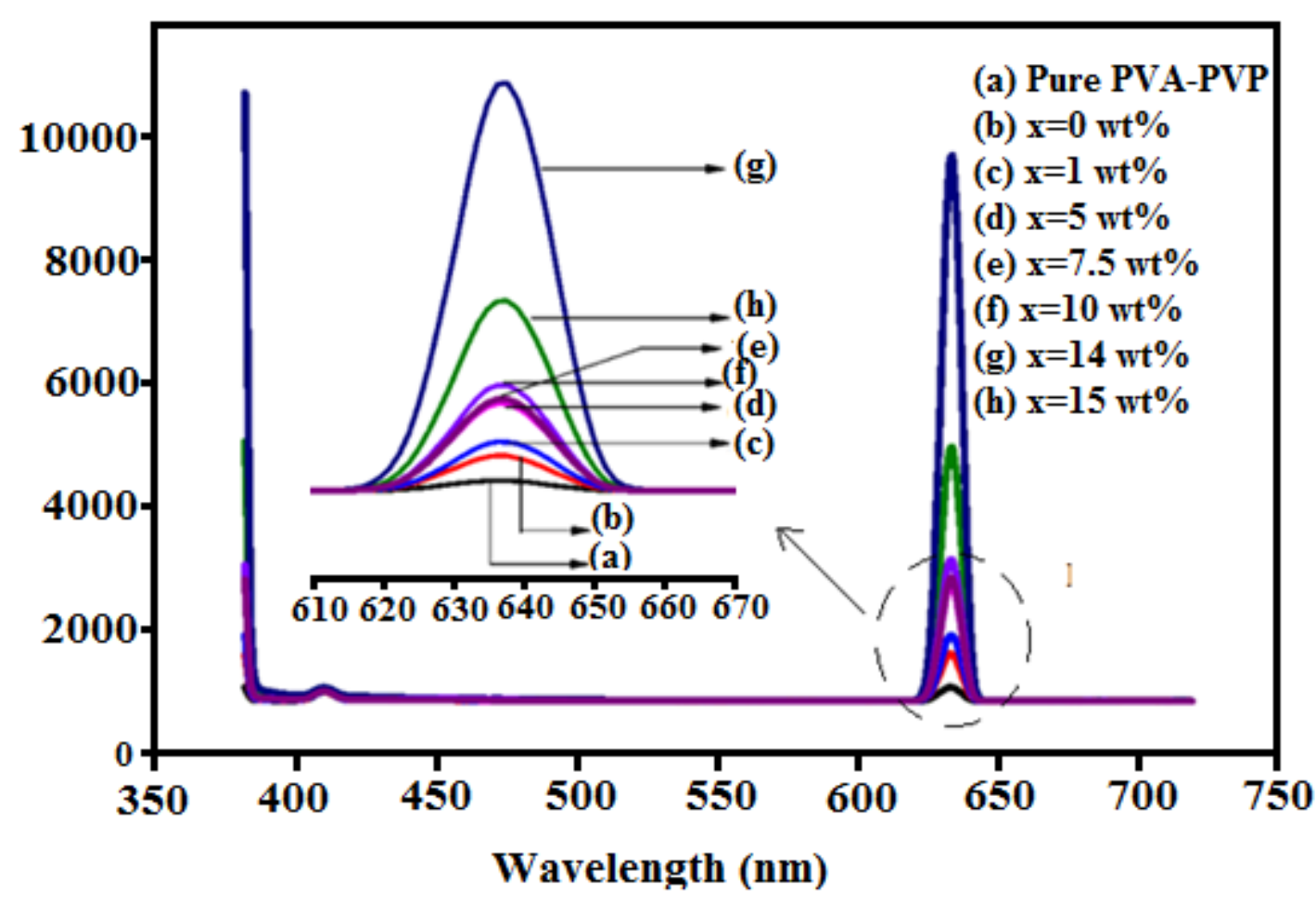

Figure 9 : PL spectra of pure PVA/PVP and filled PNCs with excitation wavelength $375 \mathrm{~nm}$

\subsection{Dielectric Studies}

Figure 10,11,12 signifies the spectra of complex dielectric permittivity (real part $\varepsilon^{\prime}$ and imaginary part $\left.\varepsilon^{\prime \prime}\right)$ and the dielectric loss tangent $(\tan \delta)$ of PVA-PVP/(15-x)CuO (x) MWCNTs composites for various concentrations at room temperature. Figure 10 explores the PNCs $\varepsilon^{\prime}$ values are decreasing with an applied frequency rise [41]. Figure 10 also shows the decrement in $\varepsilon^{\prime}$ values of unclassified PVA- PVP blend mix in the non-linear range from 14.62 to 6.32 with the rise in applied frequency from $1 \mathrm{kHz}$ to $1 \mathrm{MHz}$, whereas for PNCs, the $\varepsilon^{\prime}$ values decreased almost linearly in the range 26.97-2.81, suggesting the tunable frequency behaviour. The substantial reduction of $\varepsilon^{\prime}$ values across the lower frequency range of $x=14$ wt\% filler level are evidence of the significant impact of the nano-confinement effect in the PVA/PVP network. It is well known that the nano-confinement impact is primarily an increased impediment of dipolar units in the PVA-PVP network created by the nanofillers with a time-different electric field, which decreases the dipolar polarisation of the 
PVP/PVA(15-x)CuO(x) MWCNTs PNCs [42]. The increment in frequency towards a higher frequency range indicates that the values of $\varepsilon^{\prime}$ for PVP/PVA(15-x)CuO(x) MWCNTs PNCs for $\mathrm{x}=14 \mathrm{wt} \%$ are comparable to those of the other filler loading nanocomposites, which suggests that the nanocontainment effect plays no role in the higher frequency dielectric polarisation. The $\varepsilon^{\prime \prime}$ and Tan $\delta$ values in figures 11 and 12 decreased substantially at low frequencies and showed a reasonably steady behaviour compared to unfilled PVA-PVP mix film. The result shows that $\mathrm{x}=14 \mathrm{wt} \%$ nanofiller loading significantly decreases lowfrequency dielectric losses in the PVA-PVP mix. Furthermore, there has been a substantial reduction in the $\varepsilon^{\prime \prime}$ values of PNC films with a further rise in loading level upto $\mathrm{x}=14 \mathrm{wt} \%$. The $\varepsilon^{\prime \prime}$ and Tan $\delta$ values initially decreased slightly with the rise in frequency and slightly increased trend for higher applied frequencies (i.e. f $>10 \mathrm{kHz}$ ). For $\mathrm{x}=14 \mathrm{wt} \%$ loading level, the $\varepsilon^{\prime \prime}$ and Tan $\delta$ spectra of PVP/PVA(15-x)CuO(x) MWCNTs nanocomposites exhibit decreasing trends between $1 \mathrm{kHz}$ and $10 \mathrm{kHz}$. At the same time, the observational frequency range between $10 \mathrm{kHz}$ and $1 \mathrm{MHz}$ dielectric relaxation reduces, contributing to the conductivity [43]. Thus, $\varepsilon^{\prime \prime}$ and Tan $\delta$ these PNCs upto $\mathrm{x}=14 \mathrm{wt} \%$ show a gradual improvement in the parameter values with an increase in frequency and at higher applied frequency shows a dipolar relaxation process in these materials. 


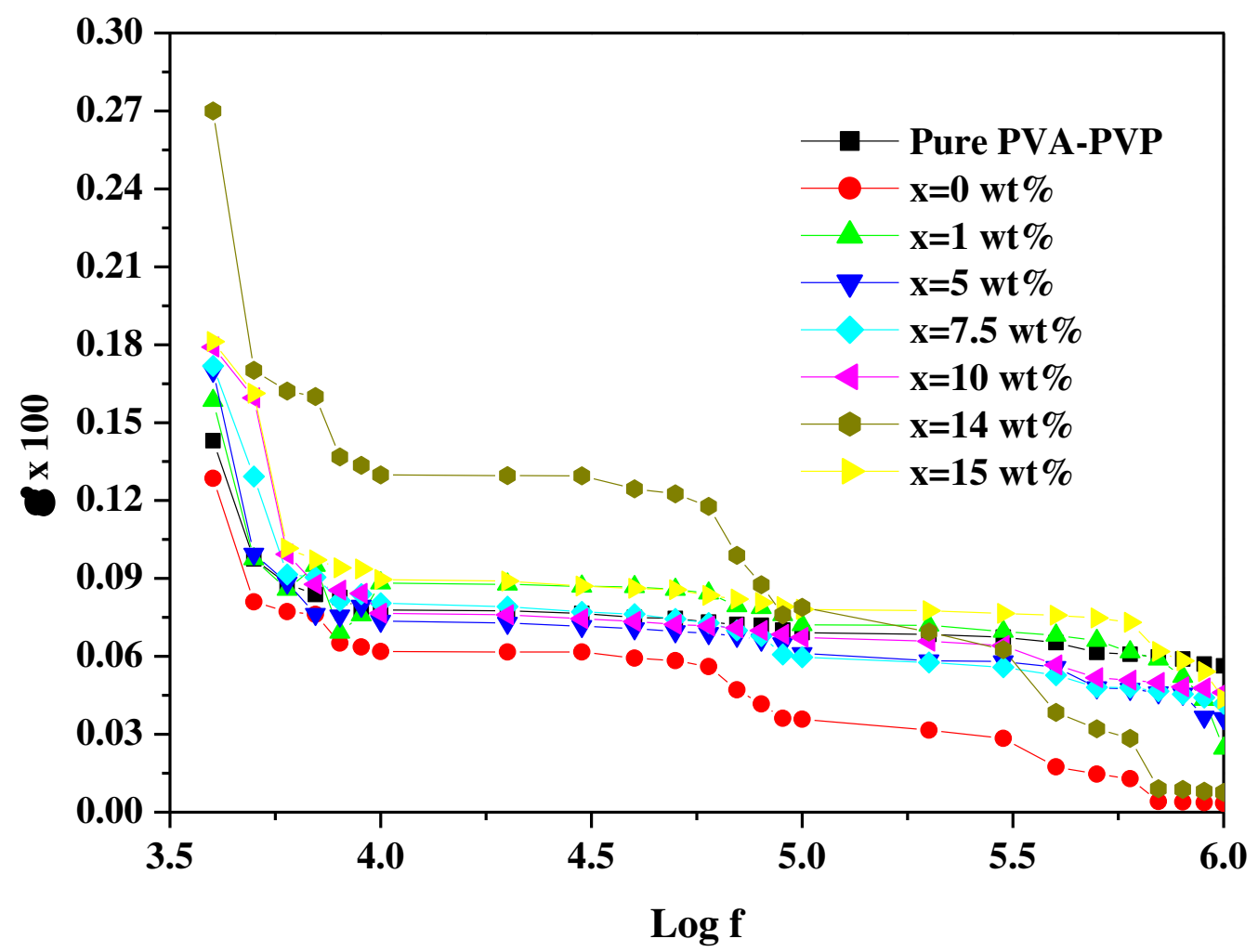

Figure 10: Deviation of real dielectric constant of PVA/PVP:(15-x)CuO(x)MWCNTs PNCs for different filler concentration. 


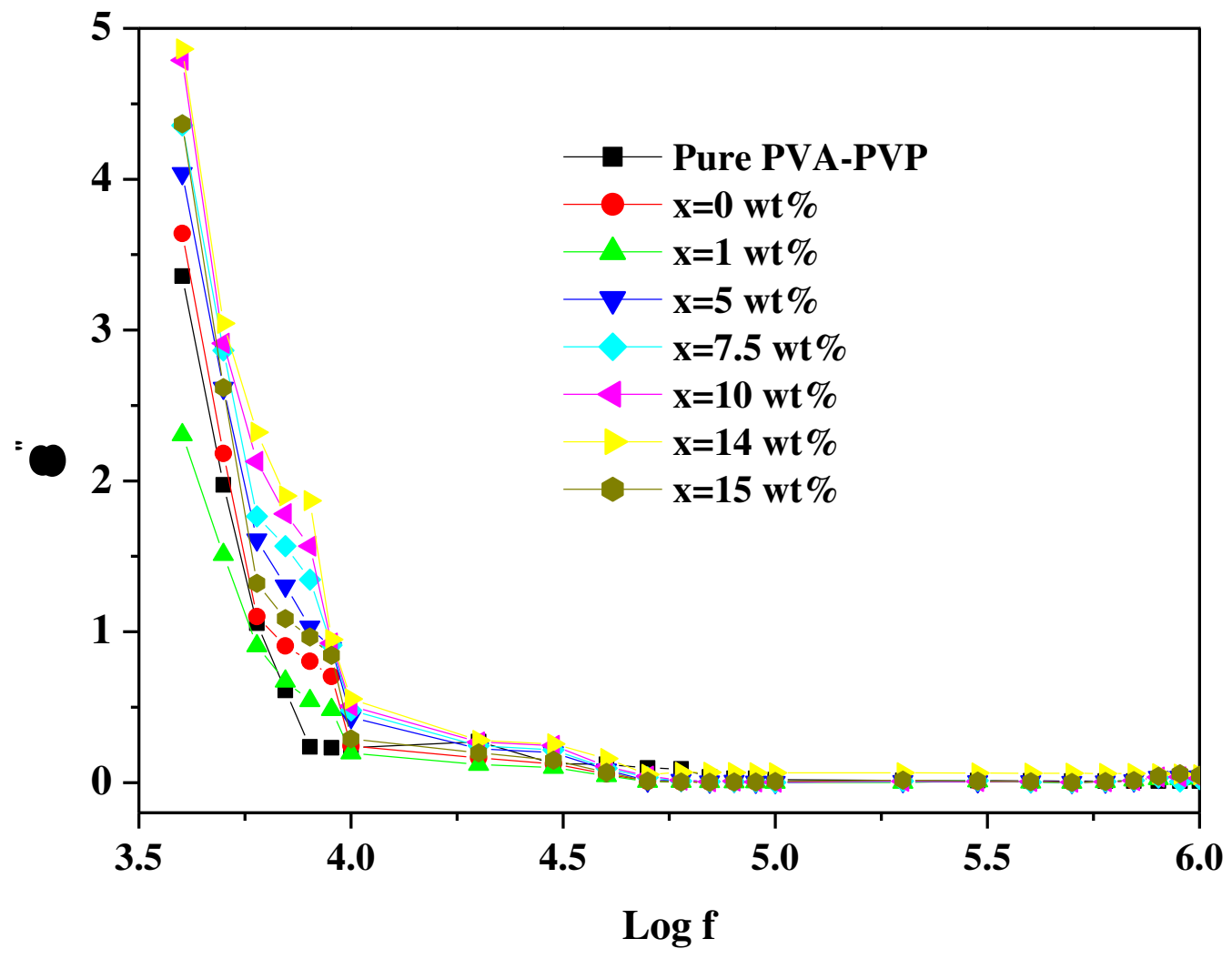

Figure 11: Variation of imaginary dielectric constant for different filler levels of PVAPVP:(15-x)CuO(x)MWCNTs PNCs. 


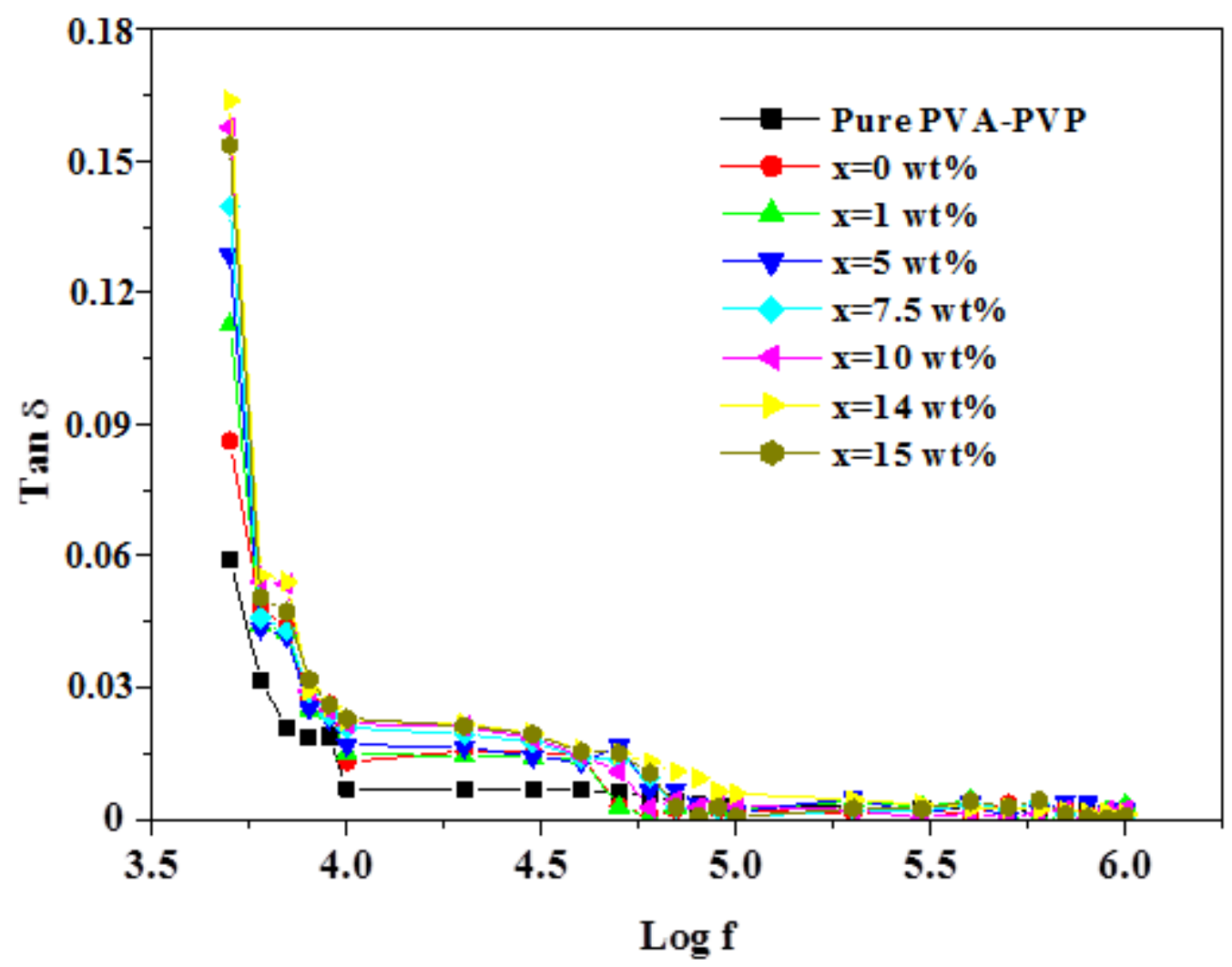

Figure 12: Variation of dielectric loss for different filler levels of PVA-PVP:(15$\mathrm{x}) \mathrm{CuO}(\mathrm{x}) \mathrm{MWCNTs}$ PNCs

\section{Conclusions}

In this current research, the effects of structural, optical, thermal, dielectric and electrical properties of copper dioxide $(\mathrm{CuO})$ nanoparticles and multiwall carbon nanotubes (MWCNTs) filled PVA and PVP blend matrix (50/50wt\%) established polymer nanocomposites (PNCs) (i.e., PVA/PVP:(15-x)CuO(x)MWCNTs for $\mathrm{x}=0,1,5,7.5,10,14$, and $15 \mathrm{wt} \%)$ are reported. X-ray diffraction investigation reports the increase in crystallinity of PNCs for $\mathrm{x}=14 \mathrm{wt} \%$ filler level. The FTIR, SEM, and AFM measurements of PVA/PVP:(15$\mathrm{x}) \mathrm{CuO}(\mathrm{x}) \mathrm{MWCNTs}$ for $\mathrm{x}=0,1,5,7.5,10,14$, and $15 \mathrm{wt} \%$ provides the information of miscible mix, PVA-PVP interaction and polymer-nanoparticle interfaces, and the influence of $\mathrm{CuO}$ and MWCNTs nanofillers on the morphology aspects on the network of PVA/PVP blend. Optical studies shows the nanofiller dispersion for $\mathrm{x}=14 \mathrm{wt} \%$ nanoloading in the PNCs matrix considerably enhances the crystalline phase, diminishing its optical energy gap to $2.31 \mathrm{eV}$. The DC conductivity values enhance to $13.35 \times 10^{-9} \mathrm{~S} / \mathrm{cm}$ with the upsurge in optimum filler level $\mathrm{x}=14 \mathrm{wt} \%$. The photoluminescence studies of PNCs exhibit exciting pinnacles at $380 \mathrm{~nm}$ and precise, strong emission bands within $650 \mathrm{~nm}$ visible range by 
disregarding a specific harmonic order of reflection. TGA studies show that strengthening the interface contact between MWCNTs with $\mathrm{CuO}$ nanofillers and PVA/PVP PNCs dispersion upto $\mathrm{x}=14 \mathrm{wt} \%$ loading level may improve thermal stability matched with pure PVA/PVP blend. The dielectric and electrical characteristics of these PNCs are investigated for an applied frequency range from $1 \mathrm{kHz}$ to $1 \mathrm{MHz}$. The enhancement in the nanofiller level upto $\mathrm{x}=14 \mathrm{wt} \%$ in the PNCs matrix leads to the development of percolating network through the PNCs. These factors boost the dielectric permittivity values substantially, owing to the decrease in the nano-confinement phenomenon. The rise in applied frequency reduces the real portions of dielectric permittivity and enhances electrical conductivity. These PVA / PVP :(15-x)CuO (x)MWCNTs having good dielectric and electrical characteristics can be used as frequency tunable dielectric PNCs in electronic devices.

\section{Conflict of Interest}

The author declares no conflict of interest.

Acknowledgements: The author is thankful to University of Jeddah, Saudi Arabia

\section{References}

1. Demir, M. M.; Memesa, M.; Castignolles, P.; Wegner, G. "PMMA/zinc oxide Nanocomposites prepared by in-situ bulk polymerization", Macromolecular Rapid Communications. 2006, 27 (10), 763-770.

2. Abdelrazek EM, Elashmawi IS, El-Khodary A, Yassin A (2010) Structural, optical, thermal and electrical studies on PVA/PVP blends filled with lithium bromide. Curr Appl Phys 10:607-613.

3. Todd Alam M, Otaigbe JU, Rhoades D, Holland GP, Cherry BR, Kotula PG (2005) Nanostructured polymer blends: Synthesis and structure. Polymer 46(26):1246812479.

4. Baskaran R, Selvasekarapandian S, Kuwata N, Kawamura J, Hattori T (2006) Conductivity and thermal studies of blend polymer electrolytes based on PVAcPMMA. Solid State Ionics 177:2679-2682.

5. Kumar KK, Ravi M, Pavani Y, Bhavani S, Sharma AK, Narasimha Rao VVR. Investigations on $\mathrm{PEO} / \mathrm{PVP} / \mathrm{NaBr}$ complexed polymer blend electrolytes for electrochemical cell applications. J Membr Sci 2014; 454:200-11. 
6. N. B. Rithin Kumar, Santhosha Acharya, A. Alhadhrami, B. M. Prasanna, S. C. Gurumurthy, Sangeetha Bhat, Role of $\mathrm{TiO} 2 / \mathrm{ZnO}$ Nanofillers in Modifying the Properties PMMA Nanocomposites for Optical Device Applications. Iran J Sci Technol Trans Sci (2021). https://doi.org/10.1007/s40995-021-01183-4

7. K. Phiwdang, S. Suphankij, W. Mekprasart, W. Pecharapa, Synthesis of CuO nanoparticles by precipitation method using different precursors, Energy Procedia, 34 (2013), pp. 740-745

8. Rajeswari N, Selvasekarapandian S, Sanjeeviraja C, Kawamura J, Asath Bahadur S (2014) A study on polymer blend electrolyte based on PVA/PVP with proton salt. Polym Bull 71:1061-1080.

9. Subba Reddy CV, Sharma AK, Narasimha Rao VVR (2006) Electrical and optical properties of a polyblend electrolyte. Polymer 47:1318-1323

10. ZD. Dai, L. Ansaloni, D.L. Gin, R.D. Noble, L.Y. Deng, J. Membr. Sci., 523 (2017), pp. 551-560.

11. B. Yalagala, S. Khandelwal, J. Deepika, S. Badhulika, Wirelessly destructible MgOPVP-graphene composite based flexible transient memristor for security applications. Mater. Sci. Semicond. Process. 104, 104673, (2019).

12. F.M. Ali, R.M. Kershi, M.A. Sayed, Y.M. AbouDeif, Evaluation of structural and optical properties of $\mathrm{Ce} 3+$ ions doped (PVA/PVP) composite films for new organic semiconductors. Physica B Condens. Matter 538, 160-166 (2018).

13. S. Mahendia, G. Kandhol, U.P. Deshpande, S. Kumar, Determination of glass transition temperature of reduced graphene oxide-poly(vinyl alcohol) composites using temperature-dependent Fourier transform infrared spectroscopy. J. Mol. Struct. 1111, 46-54 (2016).

14. R.F. Bhajantri, V. Ravindrachary, B. Poojary, A. Harisha, V. Crasta, Studies on fluorescent PVA + PVP + MPDMAPP composite films. Polym. Eng. Sci. 49(5), 903909 (2009).

15. Abdelrazek EM, Elashmawi IS, El-Khodary A, Yassin A. Structural, optical, thermal and electrical studies on PVA/PVP blends filled with lithium bromide. Curr Appl Phys 2010; 10:607-13.

16. A. Azam, A.S. Ahmed, M. Oves, M.S. Khan, A. Memic, Size-dependent antimicrobial properties of $\mathrm{CuO}$ nanoparticles against gram-positive and -negative bacterial strains. Int. J. Nanomed., 7 (2012), pp. 3527-3535 
17. Peng X, Wong SS. 2009. Functional Covalent Chemistry of Carbon Nanotube Surfaces. Adv. Mater.. 21(6):625-642. http://dx.doi.org/10.1002/adma.200801464

18. R. Jeyaraman, J. Kadarkaraithangam, M. Arumugam, R. Govindasamy, A. Abdul.Synt hesis and antimicrobial activity of copper nanoparticles, Mater. Lett., 71 (2011), pp. 114-116

19. Liu Z, Jiao L, Yao Y, Xian X, Zhang J. 2010. Aligned, Ultralong Single-Walled Carbon Nanotubes: From Synthesis, Sorting, to Electronic Devices. Adv. Mater.. 22(21):2285-2310. http://dx.doi.org/10.1002/adma.200904167

20. S.H. Park, W.J. Lee. Hierarchically mesoporous $\mathrm{CuO}$ /carbon nanofiber coaxial shellcore nanowires for lithium ion batteries, Sci. Rep., 5 (2015)

21. M. Sahooli, S. Sabbaghi, R. Saboori. Synthesis and characterization of mono sized $\mathrm{CuO}$ nanoparticles,Mater. Lett., 81 (2012), pp. 169-172

22. Zidan H M, J. Appl. Polym. Sci., 88, 1115-1120 (2003).

23. R.F. Bhajantri, V. Ravindrachary, B. Poojary, A. Harisha, V. Crasta, Studies on fluorescent PVA + PVP + MPDMAPP composite films. Polym. Eng. Sci. 49(5), 903909 (2009).

24. Rithin Kumar N B, Vincent Crasta, B M Praveen, Enhancement of optical, mechanical and micro structural properties in nanocomposite films of PVA doped with $\mathrm{WO}_{3}$ nanoparticles.International Journal of Structural Integrity, Volume 6, Number 3, 2015, pp. 338-354(17)

25. Hemanth Kumar, G.N., Lakshmana Rao, J., Gopal, N.O., Narasimhulu, K.V.C., Chakradhar, R.P.S., Varada Rajulu, A., 2004. Spectroscopic investigation Mn+2 ions doped polyvinyl alcohol films. Polymer 45, 5407-5415.

26. Abdelrazek, E.M., Abdelghany, A.M., Oraby, A.H., Asnag, G.M., 2012. Investigation of Mixed Filler Effect on Optical and Structural Properties of PEMA Films. International Journal of Engineering and Technology 12, 98-102.

27. Saini I, Rozra J, Chandak N, Aggarwal S, Sharma PK, Sharma A. Tailoring of electrical, optical and structural properties of PVA by adding Ag nanoparticles. Mater. Chem. Phys, 2013;139:802-10.

28. Davis EA, Mott NF. Conduction in non-crystalline systems. V. Conductivity, optical absorption and photoconductivity in amorphous semiconductors. Philos Mag 1970; 22:0903-22.

29. Mott NF. Conduction in non-crystalline systems: IV. Anderson localization in a disordered lattice. Philos Mag 1970; 22:7-29. 
30. Collins, B. A.; Cochran, J. E.; Yan, H.; Gann, E.; Hub, C.; Fink, R.; Wang, C.; Schuettfort, T.; McNeill, C. R.; Chabinyc, M. L.; Ade, H. Polarized X-ray scattering reveals non-crystalline orientational ordering in organic films. Nat. Mater. 2012, 11, $536-543$.

31. Noriega, R.; Rivnay, J.; Vandewal, K.; Koch, F. P.; Stingelin, N.; Smith, P.; Toney, M. F.; Salleo, A. A general relationship between disorder, aggregation and charge transport in conjugated polymers. Nat. Mater. 2013, 12, 1038-1044.

32. Kang, S. D.; Snyder, G. J. Charge-transport model for conducting polymers. Nat. Mater. 2017, 16, 252-257

33. Patel, S. N.; Glaudell, A. M.; Peterson, K. A.; Thomas, E. M.; O’Hara, K. A.; Lim, E.; Chabinyc, M. L. Morphology controls the thermoelectric power factor of a doped semiconducting polymer. Sci. Adv. 2017, 3, e1700434.

34. H.-S. Kim, H.-S. Yang, H.-J. Kim, H.-J. Park, J. Therm. Anal. Calorim. 76 (2004), 395-404.

35. Zuo, G.; Liu, X.; Fahlman, M.; Kemerink, M. High Seebeck Coefficient in Mixtures of Conjugated Polymers. Adv. Funct. Mater. 2018, 28, 1703280.

36. A.W. Coats, J.P. Redfern, Nature 201 (1964) 68-69.

37. A. Broido, J. Polym. Sci. A 2 (7) (1969) 1761-1773.

38. Gananatha Shetty B, Vincent Crasta, Rithin Kumar N B, Rajesh K, Raghavendra Bairy, Parutagouda Shankaragouda Patil, Promising PVA/TiO2, CuO filled nanocomposites for electrical and third order nonlinear optical applications, Optical Materials, Volume 95, 2019,109218, https://doi.org/10.1016/j.optmat.2019.109218.

39. E.S.Mora, E.G.Barojas, E.R.Rojas, R.S.Gonzalez, Sol. Energy Mater. Sol. Cells 91 (2007) 1412-1415.

40. M.Mazzera, M.Zha, D.Calestani, A.Zappettini, L.Lazzarini, G.Salviati, L.Zanotti, Nanotechnology 18 (2007) 355707.

41. N B Rithin Kumar, Vincent Crasta, B M Praveen, "Dielectric and electric conductivity studies of PVA (Mowiol 10-98) doped with MWCNTs and $\mathrm{WO}_{3}$ nanocomposites films", Materials Research Express, 3 (5), 055012, 2016.

42. D Mardare, G I Rusu, "comparison of the dielectric properties for doped and undoped $\mathrm{TiO}_{2}$ thin films", Journal of Optoelectronics and Advanced Materials, 2004, 6, 333 336. 
43. V Rao, P V Ashokan, M H Shridhar, "Studies of dielectric relaxation and a.c. conductivity in cellulose acetate hydrogen phthalate-poly (methyl methacrylate) blends", Materials Science and Engineering A, 2000, 281, 213-220. 